\title{
Crystal Structure of Another Polymorph of 1,4-Anthraquinone
}

\author{
Chitoshi Kitamura, ${ }^{\dagger}$ Nobuhiro Kawatsuki, and Akio Yoneda \\ Department of Materials Science and Chemistry, Graduate School of Engineering, University of Hyogo, \\ 2167 Shosha, Himeji, Hyogo 671-2201, Japan
}

\begin{abstract}
The crystal structure of another polymorph of 1,4-anthraquinone was determined. The compound crystallizes in monoclinic, space group $P 2{ }_{1} / n$ with $a=7.301(1), b=9.674(2), c=13.831(2) \AA, \beta=93.175(8) \AA, V=975.5(3) \AA^{3}, Z=4$. There is antiparallel $\pi-\pi$ stacking between aromatic rings. The packing arrangement is different from another crystal structure for 1,4-anthraquinone (space group $P 2_{1} / b$ with $a=8.430(1), b=19.846(2), c=5.927(1) \AA, \gamma=100.21(2)^{\circ}$, CCDC code: COBBIE04).
\end{abstract}

(Received July 27, 2006; Accepted November 6, 2006; Published on web December 15, 2006)

1,4-Anthraquinone (Fig. 1) is an important molecule as a dienophile for the Diels-Alder reaction and as a kind of redox system. To the best of our knowledge, two polymorphic crystal structures of 1,4-anthraquinone have already been reported in RefCode COBBIE, ${ }^{1}$ COBBIE02, ${ }^{2}$ COBBIE03, ${ }^{1}$ and $\mathrm{COBBIE}^{3} 4^{3}$ from CCDC, in which COBBIE and COBBIE02 are isomorphic and a pair of COBBIE03 and COBBIE04 is another isomorph. The atomic coordinates were elucidated in only COBBIE04. Recently, we performed an X-ray analysis of

Table 1 Crystal and experimental data

Formula: $\mathrm{C}_{14} \mathrm{H}_{8} \mathrm{O}_{2}$

Formula weight $=208.22$

Crystal color, habit: red, needle

Crystal size: $0.50 \times 0.03 \times 0.03 \mathrm{~mm}$

Crystal system: monoclinic

Space group: $P 2_{1} / n \quad Z=4$

$T=223 \mathrm{~K}$

$a=7.301(1) \AA$

$b=9.674(2) \AA$

$c=13.831(2) \AA$

$\beta=93.175(8)^{\circ}$

$V=975.5(3) \AA^{3}$

$D_{\text {calc }}=1.418 \mathrm{~g} / \mathrm{cm}^{3}$

No. of reflections used $=1417(I>2.00 \sigma(I))$

$2 \theta_{\max }=55.0^{\circ}$ with Mo $K_{\alpha}(0.71070 \AA)$

$R=0.083[I>2 \sigma(I) ; 1417$ refs. $]$

$R_{\mathrm{w}}=0.162$ [all $2217 \mathrm{refs}$.]

$(\Delta / \sigma)_{\max }=0.001$

$(\Delta \rho)_{\max }=0.22 \mathrm{e}^{-3}$

$(\Delta \rho)_{\min }=-0.16 \mathrm{e}^{-3}$

Measurement: Rigaku/MSC Mercury CCD

Program system: teXsan

Structure determination: direct method (SIR92)

Refinement: full-matrix least-squares

CCDC 614483 contains the supplementary crystallographic data for this paper. These data can be obtained free of charge from The Cambridge Crystallographic Data Centre via www.ccdc.cam.ac.uk/data_request/cif.

$\doteqdot$ To whom correspondence should be addressed.

E-mail: kitamura@eng.u-hyogo.ac.jp needle-shaped 1,4-anthraquinone, and found that the crystal structure is different from that for COBBIE04, namely, another polymorph. We now refer to our crystal structure as the $\beta$-form (COBBIE04 as $\alpha$-form). We report here on the crystal structure of another polymorph of 1,4-anthraquinone in detail.

1,4-Anthraquinone was prepared in $88 \%$ yield $(764 \mathrm{mg})$ by the reduction of 1,4-dihydroxy-9,10-anthraquinone (1.0 g, 4.19 mmol) with $\mathrm{NaBH}_{4}(1.0 \mathrm{~g}, 26.5 \mathrm{mmol})$ in methanol $(60 \mathrm{~mL})$, followed by a treatment with $50 \% \mathrm{AcOH}(60 \mathrm{~mL})$. Single crystals in the $\beta$-form for X-ray crystallography were grown from a toluene-ethanol solution. The selection of toluene and ethanol solvents afforded the $\beta$-form exclusively. The X-ray data were collected using a Rigaku/MSC Mercury CCD diffractometer with graphite monochromated Mo- $K_{\alpha}(\lambda=$ $0.71070 \AA$ ) radiation at $223 \mathrm{~K}$. The structure was solved by a<smiles>O=C1C=CC(=O)c2cc3ccccc3cc21</smiles>

Fig. 1 Chemical diagram.

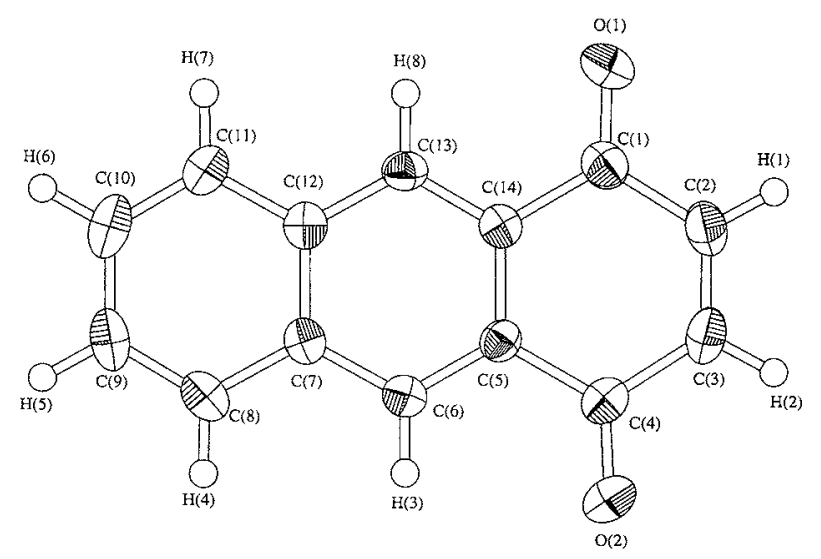

Fig. 2 ORTEP drawing of the title compound with atom labeling. The thermal ellipsoids are drawn at the $50 \%$ probability level. 


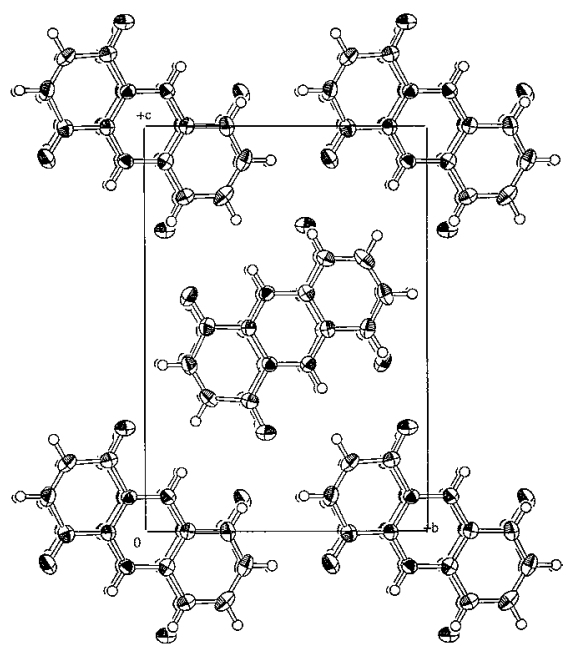

Fig. 3 Packing diagram projected onto the $b c$ plane.

Table 2 Atomic coordinates and equivalent isotropic thermal parameters $\left(B_{\text {eq }}\right)$

\begin{tabular}{ccccc}
\hline Atom & $x$ & $y$ & $z$ & $B_{\text {eq }}\left(\AA^{2}\right)$ \\
\hline $\mathrm{O}(1)$ & $0.1418(3)$ & $0.3436(2)$ & $1.0808(1)$ & $4.33(5)$ \\
$\mathrm{O}(2)$ & $0.1357(3)$ & $0.0711(2)$ & $0.7441(1)$ & $4.22(5)$ \\
$\mathrm{C}(1)$ & $0.1433(3)$ & $0.2787(3)$ & $1.0056(2)$ & $2.85(5)$ \\
$\mathrm{C}(2)$ & $0.0824(3)$ & $0.3429(3)$ & $0.9128(2)$ & $3.26(6)$ \\
$\mathrm{C}(3)$ & $0.0795(3)$ & $0.2743(3)$ & $0.8299(2)$ & $3.16(6)$ \\
$\mathrm{C}(4)$ & $0.1366(3)$ & $0.1283(3)$ & $0.8227(2)$ & $2.69(5)$ \\
$\mathrm{C}(5)$ & $0.1950(3)$ & $0.0576(2)$ & $0.9143(1)$ & $2.19(5)$ \\
$\mathrm{C}(6)$ & $0.2441(3)$ & $-0.0794(2)$ & $0.9136(2)$ & $2.45(5)$ \\
$\mathrm{C}(7)$ & $0.3016(3)$ & $-0.1496(2)$ & $0.9997(2)$ & $2.27(5)$ \\
$\mathrm{C}(8)$ & $0.3515(3)$ & $-0.2908(2)$ & $1.0007(2)$ & $3.09(6)$ \\
$\mathrm{C}(9)$ & $0.4089(3)$ & $-0.3533(3)$ & $1.0850(2)$ & $3.34(6)$ \\
$\mathrm{C}(10)$ & $0.4177(3)$ & $-0.2797(3)$ & $1.1724(2)$ & $3.55(6)$ \\
$\mathrm{C}(11)$ & $0.3690(3)$ & $-0.1433(3)$ & $1.1748(2)$ & $2.97(6)$ \\
$\mathrm{C}(12)$ & $0.3103(3)$ & $-0.0744(2)$ & $1.0884(2)$ & $2.43(5)$ \\
$\mathrm{C}(13)$ & $0.2589(3)$ & $0.0665(2)$ & $1.0875(2)$ & $2.43(5)$ \\
$\mathrm{C}(14)$ & $0.2016(3)$ & $0.1312(2)$ & $1.0030(2)$ & $2.25(5)$ \\
\hline
\end{tabular}

$B_{\text {eq }}=(8 / 3) \pi^{2}\left(U_{11}\left(a a^{*}\right)^{2}+U_{22}\left(b b^{*}\right)^{2}+U_{33}\left(c c^{*}\right)^{2}+2 U_{12}\left(a a^{*} b b^{*}\right) \cos \gamma+\right.$ $\left.2 U_{13}\left(a a^{*} c c^{*}\right) \cos \beta+2 U_{23}\left(b b^{*} c c^{*}\right) \cos \alpha\right)$.

direct method using SIR92. ${ }^{4}$ All of the non-hydrogen atoms were refined anisotoropically by the full-matrix least-squares method. The positions of the hydrogen atoms were calculated geometrically, and were not refined. All calculations were performed using the teXsan program package. ${ }^{5}$ Crystal and experimental data are listed in Table 1. In Figs. 2 and 3, the molecular structure and a packing diagram are shown. The final positional parameters are given in Table 2, and selected bond lengths, bond angles, and dihedral angles are listed in Table 3.

The X-ray analysis reveals that the molecule is essentially planar. Not surprisingly, there is no significant difference in the molecular structure between the $\alpha$ - and $\beta$-forms. For example, the distances of $\mathrm{O}(1)-\mathrm{C}(1)$ and $\mathrm{O}(2)-\mathrm{C}(4)$ in $\beta$-form are 1.216(3) and $1.219(3) \AA$, respectively, whose values are similar to those of 1.223 and $1.225 \AA$. The other bond lengths and bond angles are within the expected ranges. The molecule in the $\beta$-form adopts a herringbone arrangement with $\pi-\pi$ stacking. As shown in Fig. 3, the molecules form face-to-face slipped $\pi-\pi$ stacking
Table 3 Selected bond lengths ( $)$, bond angles $\left({ }^{\circ}\right)$ and dihedral angles $\left({ }^{\circ}\right)$

\begin{tabular}{|c|c|c|c|c|c|c|c|c|c|}
\hline$O(1)$ & \multicolumn{2}{|c|}{$C(1)$} & \multicolumn{2}{|c|}{$1.216(3)$} & \multicolumn{2}{|c|}{$\mathrm{O}(2)$} & \multicolumn{2}{|l|}{$C(4)$} & $1.219(3)$ \\
\hline$C(1)$ & \multicolumn{2}{|c|}{$C(2)$} & \multicolumn{2}{|c|}{$1.473(3)$} & \multicolumn{2}{|c|}{$\mathrm{C}(1)$} & \multicolumn{2}{|c|}{$\mathrm{C}(14)$} & $1.489(3)$ \\
\hline$c(2)$ & \multicolumn{2}{|c|}{$\mathrm{C}(3)$} & \multicolumn{2}{|c|}{$1.324(3)$} & \multicolumn{2}{|c|}{$\mathrm{C}(3)$} & \multicolumn{2}{|c|}{$C(4)$} & $1.478(4)$ \\
\hline$C(4)$ & \multicolumn{2}{|c|}{ C(5) } & \multicolumn{2}{|c|}{$1.482(3)$} & \multicolumn{2}{|c|}{$C(5)$} & \multicolumn{2}{|l|}{$C(6)$} & $1.374(3)$ \\
\hline$C(5)$ & \multicolumn{2}{|c|}{ C(14) } & \multicolumn{2}{|c|}{$1.416(3)$} & \multicolumn{2}{|c|}{$C(6)$} & \multicolumn{2}{|l|}{$\mathrm{C}(7)$} & $1.414(3)$ \\
\hline$C(7)$ & \multicolumn{2}{|c|}{$\mathrm{C}(8)$} & \multicolumn{2}{|c|}{$1.413(3)$} & \multicolumn{2}{|c|}{$C(7)$} & \multicolumn{2}{|c|}{$C(12)$} & $1.425(3)$ \\
\hline$C(8)$ & \multicolumn{2}{|c|}{$\mathrm{C}(9)$} & \multicolumn{2}{|c|}{$1.360(3)$} & \multicolumn{2}{|c|}{$C(9)$} & \multicolumn{2}{|c|}{$c(10)$} & $1.401(4)$ \\
\hline $\mathrm{C}(10)$ & \multicolumn{2}{|c|}{$C(11)$} & \multicolumn{2}{|c|}{$1.367(4)$} & \multicolumn{2}{|c|}{$C(11)$} & \multicolumn{2}{|c|}{ C(12) } & $1.415(3)$ \\
\hline $\mathrm{C}(12)$ & \multicolumn{2}{|c|}{ C(13) } & 1.413 & & $\mathrm{CO}$ & & C(14 & & $1.371(3)$ \\
\hline$O(1)$ & $\mathrm{C}(1)$ & $\mathrm{C}(2$ & & $120.7(2)$ & $O(1)$ & $C(1)$ & & $(14)$ & 122.1(2) \\
\hline$O(2)$ & $C(4)$ & $\mathrm{C}(3$ & & $120.4(2)$ & $\mathrm{O}(2)$ & $C(4)$ & & $c(5)$ & $122.7(2)$ \\
\hline$C(I)$ & $C(2)$ & $\mathrm{C}(\mathrm{S}$ & & $122.2(2)$ & $C(2)$ & $C(3)$ & & (4) & $123.1(2)$ \\
\hline$C(3)$ & $C(4)$ & $\mathrm{C}(5$ & & $116.9(2)$ & C(4) & $C(5)$ & & $(6)$ & $120.1(2)$ \\
\hline$C(5)$ & $C(6)$ & $C(7$ & & $121.5(2)$ & $C(6)$ & $\mathrm{C}(7)$ & & (8) & $122.4(2)$ \\
\hline$C(7)$ & $C(8)$ & $\mathrm{C}(9$ & & $120.3(2)$ & $C(8)$ & $\mathrm{C}(9)$ & & $(10)$ & $120.7(2)$ \\
\hline $\mathrm{C}(9)$ & $C(10)$ & $\mathrm{C}(1$ & & $120.8(2)$ & $C(10)$ & C(11) & & $(12)$ & $120.1(2)$ \\
\hline$C(11)$ & $C(12)$ & $\mathrm{C}(1$ & & $122.0(2)$ & $\mathrm{C}(12)$ & $C(13)$ & & (14) & $121.1(2)$ \\
\hline$C(1)$ & $C(14)$ & $\mathrm{C}(1$ & & $119.4(2)$ & & & & & \\
\hline$O(1)$ & $C(1)$ & $C(2)$ & $\mathrm{C}(3)$ & $-178.8(2)$ & $O(2)$ & $C(4)$ & $C(5)$ & $C(14)$ & $177.0(2)$ \\
\hline C(1) & $\mathrm{C}(2)$ & $\mathrm{C}(3)$ & $C(4)$ & $0.0(4)$ & $C(1)$ & $C(14)$ & $C(5)$ & $C(4)$ & $2.3(3)$ \\
\hline$C(6)$ & $C(5)$ & C(14) & $C(13)$ & $0.8(3)$ & $\mathrm{C}(6)$ & $\mathrm{C}(7)$ & $C(12)$ & C(13) & $0.9(3)$ \\
\hline$C(8)$ & $C(7)$ & $C(12)$ & $C(11)$ & $0.1(3)$ & $C(8)$ & $\mathrm{C}(9)$ & $C(10)$ & $\mathrm{C}(11)$ & $0.0(4)$ \\
\hline
\end{tabular}

along the direction of the $a$-axis. The interplanar distance is $3.423 \AA$. On the other hand, in the $\alpha$-form, there is no remarkable $\pi$-overlap of the aromatic rings, although the molecule takes a herringbone structure. In addition to $\pi-\pi$ stacking, the molecules in the $\beta$-form are approximately antiparallel with respect to one another. This orientation is ascribed to dipole-dipole interactions, because 1,4anthraquinone has a weak dipole moment along the molecular long axis, whose value was estimated to be 2.535 Debye by a B3LYP/6-31G(d) DFT calculation.

In summary, we observed the similarities and differences between the crystal structures in $\alpha_{-}$and $\beta$-form 1,4 anthraquinone. The packing in the $\beta$-form was rationalized by dipole-dipole interactions.

\section{Acknowledgements}

We thank the Research Center for Molecular-scale Nanoscience, the Institute for Molecular Science, for assistance in obtaining X-ray data. This work was partially supported by a Grant-in-Aid (No. 18750123) from the Ministry of Education, Culture, Sports, Science and Technology, Japan. The Hyogo Science and Technology Association is gratefully acknowledged for financial support.

\section{References}

1. M. Alleaume and R. Darrouy, Acta Cryst., 1961, 14, 1202.

2. W. A. Caspari, Proc. Roy. Soc. (London), 1932, A136, 82.

3. A. V. Dzyabchenko and V. E. Zavodnik, Zh. Strukt. Khim., 1984, 25, 177: Chem. Abstr., 1984, 101, 15389m.

4. A. Altomare, M. C. Burla, M. Camalli, M. Cascarano, C. Giacovazzo, A. Guagliardi, and G. Polidori, J. Appl. Cryst., 1994, 27, 435.

5. Crystal Structure Analysis Package, Molecular Structure Corporation, 1985 \& 2004. 